\title{
Clinical management of nondialysis patients with chronic kidney disease: a retrospective observational study. Data from the SONDA study (Survey Of Non-Dialysis outpAtients)
}

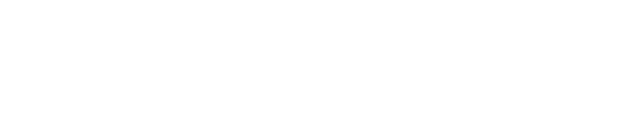

\author{
Massimo Morosetti ${ }^{1}$ \\ Antonio Gorini² \\ Anna Maria Costanzo² \\ Silvia Cipriani' \\ Sara Dominijanni' \\ Colin G Egan ${ }^{3}$ \\ Laura Zappalà' \\ Umberto di Luzio Paparatti \\ 'Nephrology and Dialysis Department, \\ 'G.B. Grassi' Hospital, Ostia \\ Lido, Rome, Italy; ${ }^{2}$ Abbott S.r.I., \\ Campoverde (LT), Rome, Italy; \\ ${ }^{3}$ Primula Multimedia S.r.l., Pisa, Italy
}

Correspondence: Anna Maria Costanzo Head of Medical Affairs SH, Abbott S.r.l, 040I I Campoverde (LT), Roma, Italy Tel +39692892 2256

$\mathrm{Fax}+396929071066$

Email annamaria.costanzo@abbott.com
Background: A lack of awareness of chronic kidney disease (CKD) often results in delayed diagnosis and inadequate treatment.

Purpose: The objective of this study was to assess the therapeutic management and outcome of nondialysis CKD patients.

Methods: Three hundred ninety-seven patients (54.9\% males aged $67.5 \pm 14.6$ years) were retrospectively screened at the Nephrology Department, GB Grassi Hospital, Rome, Italy. After a baseline visit, patient data were collected every 6 months for a total of 24 months. Clinical characteristics were measured at baseline, then the following outcomes were measured every 6 months: staging of CKD, presence of concomitant diseases, treatment and adherence to Kidney Disease Outcomes Quality Initiative (K/DOQI) guidelines for anemia management.

Results: Three hundred sixty-eight (92.7\%) patients attended at least one visit and $92(23.2 \%)$ patients attended all four visits. Patients were mainly referred to a nephrologist for chronic renal failure (61.7\%) or hypertension (42.8\%). At baseline, $79.6 \%$ of patients had previous hospitalization and $79.1 \%$ were receiving antihypertensive medication. Serum creatinine and/or glomerular filtration rate was examined in $>90 \%$ of patients, whereas parathyroid hormone was rarely examined (5.5\%). Vitamin D supplementation was received by $6.5 \%$ of patients. The majority of patients were staged at 3 or 4 CKD (32\% and $23.9 \%$, respectively) and did not significantly change over time. The use of antithrombotic, antilipidemic and erythropoietin medication increased over the four surveys. The majority of patients $(86.8 \%)$ achieved hemoglobin K/DOQI target levels.

Conclusion: These findings demonstrate a current lack of attention of CKD and related disorders (mineral metabolism, electrolyte balance, and anemia) at the level of the general practitioner (GP) and non-nephrology specialist, which can result in both delayed referral and inadequate treatment. By increasing both awareness of CKD and the coordinated relationship between GPs and nephrologists, patient clinical and therapeutic outcome may be improved.

Keywords: chronic kidney disease, metabolic bone disorders, predialysis, renal failure

\section{Introduction}

The mortality and morbidity rate for kidney failure patients continues to remain high, despite developments in dialysis and pharmacological treatment. ${ }^{1-4}$ It is recognized that much of the disease burden is well established prior to the initiation of dialysis therapy. ${ }^{5,6}$ The modification of disease progression and risk factors associated with poor outcomes has therefore become an important priority. The economic costs associated with the management of end-stage renal disease (ESRD) is a challenge for the public 
health system, and action plans are needed to face the current and expected increasing burden of this disease. ${ }^{7,8}$

Anemia in patients with chronic kidney disease (CKD) is treated with erythropoiesis-stimulating agents (ESAs), intravenous (IV) or oral iron, and less commonly, blood transfusions. Recommendations for clinical practice promulgated by the National Kidney Foundation Kidney Disease Outcomes Quality Initiative (NKF-K/DOQI) vary according to patient hemodialysis status, the underlying cause of anemia, and other factors. ${ }^{9}$ Despite the importance placed on treating anemia in patients with $\mathrm{CKD}$, many still receive inadequate treatment, as evidenced by the low hemoglobin $(\mathrm{Hb})$ levels often seen in individuals with CKD. ${ }^{10,11}$

In Italy, CKD is relatively unknown and underestimated and, consequently, the number of patients with CKD (stages 1-4) is underestimated. ${ }^{12}$ The Italian Registry of Dialysis and Transplantation only collect data for patients on dialysis and transplantation. There is not a registry available for patients with CKD and little information on the outpatient management adopted in Italian centers is currently available. A large observational multicenter study (SIR-SIN) was performed by the Italian Society of Nephrology (SIN) to obtain a more detailed picture of clinical practice in Italy relating to the diagnosis and management of CKD. ${ }^{13}$ The Italian survey highlighted important deviations of clinical policies at the central level from guideline recommendations. More recently in the Cardiovascular risk in Renal patients of the Health Examination Survey (CARHES), the prevalence of nondialysis CKD stages $1-5$ was shown to be approximately $8 \%$ in Italy, underlying the importance of awareness of CKD in Italy. ${ }^{14}$

Although important data on guideline adherence across Italy was obtained, information specific to the management of CKD and patient outcome over time (ie, from a longitudinal study) was not reported. ${ }^{13}$ Therefore, the aim of the present study was to retrospectively collect data over a 2-year period on treatment and adherence to K/DOQI guidelines for anemia management, in addition to CKD staging and changes in biochemical parameters.

\section{Materials and methods \\ Patients}

Data collection was retrospective, from a large database ( $~ 9000$ subjects) activated in 1995, derived from the Department of Nephrology, GB Grassi Hospital, Rome, Italy. This hospital is the only nephrological reference point for a population of approximately 320,000 (residential population on December 31, 2009, calculated from the local census). The Survey Of Non-Dialysis outpAtients study (SONDA) collected data for patients $(n=397)$ who met the inclusion criteria. Inclusion criteria included: patients that had undergone a visit between January 1, 2010 to 30/06/2010; patients $>18$ years; who were observed for at least 6 months; that signed an informed consent form; that arrived for a nephrological observation for a renal related disease or hypertension. Exclusion criteria included recent ( $<2$ weeks) acute coronary syndromes, acute vascular events, or acute kidney injury. Other exclusion criteria were the presence of any of the following self-reported medical conditions: autoimmune diseases and acute or chronic infection.

After an initial baseline visit, where we evaluated the eligibility of the subject and obtained signed informed consent forms, data were collected retrospectively from a database every 6 months. In this work, we have presented data from the oldest to the most recent, for clarity purposes. To evaluate the history of CKD we chose a subgroup of subjects who attended at least four visits (observed for 2 years or more).

\section{Study objectives and parameters measured}

A first visit was conducted to obtain baseline demographic and clinical patient data including the following information: (1) disease for which a visit was requested with a nephrologist, (2) presence and type of previous hospitalizations, (3) presence and type of other current pathological diseases, (4) current medication, and (5) the flow of patients (ie, number of patients attending each visit). Additional information was collected by a nephrologist at each visit every semester to determine: (1) the general conditions, (2) the staging and progression of CKD, (3) concomitant diseases and associated hospitalizations, (4) the therapeutic scenario, (5) adhesion to guidelines. In particular in this paper, the adherence to $\mathrm{K} / \mathrm{DOQI}$ guidelines of the NKF on the management of anemia and of CKD-MBD (mineral and bone disorder) ${ }^{9}$ and conservative treatment of CKD were assessed. ${ }^{6} \mathrm{Hb}$ stability was defined as having $\mathrm{Hb}$ values $\geq 11 \mathrm{~g} / \mathrm{dL}$ for the four visits or instable when $\mathrm{Hb}$ values dropped $<11 \mathrm{~g} / \mathrm{dL}$ for at least one visit. Renal function was evaluated through the measurement of serum creatinine and estimated glomerular filtration rate (eGFR) by the abbreviated Modification of Diet in Renal Disease (MDRD) equations for nonstandardized creatinine. CKD was classified into five stages according to Kidney Disease: Improving Global Outcomes guidelines. ${ }^{15}$

\section{Statistical analysis}

All data are presented as mean \pm standard deviation (SD) or percent. Statistical analysis was performed with Instat 
(GraphPad, La Jolla, CA, USA) or SPSS for Windows (version 15.0; IBM, Armonk, NY, USA). Nonparametric continuous variables were compared by the Mann-Whitney test. Comparisons between two groups with normally distributed variables were analyzed by unpaired $t$-test. Categorical variables were analyzed by Fisher's exact test. Comparisons between three or more groups were performed by one-way analyses of variance, followed by Bonferroni post-hoc test. Where comparisons were made, quoted $P$ values are twotailed; $\mathrm{n}$ values refer to the number of patients examined. $P<0.05$ was considered statistically significant.

\section{Results}

\section{Baseline demographic characteristics for entire patient cohort}

The SONDA study was conducted on 397 patients who attended visits from January 1, 2010 to June 30, 2010. Patient baseline and demographic clinical characteristics by staging of CKD are presented in Table 1. The mean age of patients at baseline was $67.5 \pm 14.6$ and $54.9 \%(n=218)$ were males. The majority of patients were referred to the Nephrology Department by a general practitioner (GP) (62.2\%). Most frequent reasons for referral included chronic renal failure $(61.7 \%)$ and/or hypertension (42.8\%). Of those observed at the first visit, $79.6 \%$ had a history of hospitalizations, which were primarily in general surgery (excluding vascular access surgery) (70.6\%), followed by cardiology (37\%), and general medicine $(25.6 \%)$. Although a high proportion of patients provided creatinine $(92.4 \%)$ none had eGFR calculated by their GP (eGFR were calculated by nephrologists), and only a small number of patients had intact parathyroid hormone (iPTH) that was dosed (5.5\%). Furthermore, treatment with any form of vitamin $\mathrm{D}$ therapy was very rare $(6.5 \%)$. At the first visit, $73.3 \%$ were diagnosed with hypertension and 31\% with diabetes mellitus and/or heart disease. More than half of patients had at least one other comorbid condition. From the original study population $(n=397), 368$ had an observation period of 6 months; 279 patients had an observation period of 12 months; 170 patients had an observation period of 18 months; and 92 patients $(23.2 \%)$ had an observation period of 24 months. All further analysis is based on this subgroup of patients that had a longer follow-up period (at least four visits).

\section{Staging of CKD}

Staging of CKD for patients that attended the four visits is presented in Figure 1A. Generally, staging of CKD increased over the first three visits, decreasing at the fourth visit.
The proportion of patients with stage 4 or 5 CKD increased over the four visits (Figure 1A). This deterioration is also reflected by the number of patients who demonstrated increased staging over the first three visits. However no discernible difference was noted at 24 months when compared to baseline levels (Figure 1B).

\section{Clinical and biochemical parameters in patients over the four visits}

Apart from patients diagnosed with malignant neoplasms or metabolic acidosis, the proportion of patients (from the original study population, $n=397$ ) with all other concomitant diseases significantly increased over the four visits (Figure 2). This increase was paralleled in patients who attended all four visits $(n=92)$, but did not reach statistical significance (Table 2). The frequency of patients with concomitant vascular complications also increased over the four visits (Table 2). Of the biochemical parameters measured, only levels of serum blood urea nitrogen levels increased in a time-dependent manner, although this increase was not statistically significant (Table 2). Levels of serum $\mathrm{Hb}$ were stable over the four visits. In addition, the number of patients receiving antithrombotic (eg, aspirin), antilipidemic (eg, statin), and erythropoietin (EPO; eg, beta epoetin or darbepoetin) medication increased over the four surveys, the greatest increase (although not reaching statistical significance) being observed in EPO treatment (Table 2 and Figure 3A). The majority of patients were treated using antihypertensive $(>80 \%)$, diuretic $(>60 \%)$, or antithrombotic medication $(>50 \%)$. In contrast, at the end of the study period ( 24 months), only $25 \%$ of patients were treated using vitamin D supplementation, 15.2\% iron base, and $3.3 \%$ calcium carbonate. Symptoms reported from patients over time are shown in Figure 3B. Overall, the frequency of symptoms increased over the four visits, with a statistically significant increase only observed in patients experiencing nausea $(P=0.025)$.

\section{Anemia and bone mineral metabolism}

Patient distribution among $\mathrm{Hb}$ levels over the four visits is shown in Table 3. Although there was a significant increase in the number of patients who had $\mathrm{Hb}$ values $<11 \mathrm{~g} / \mathrm{dL}$ over the four visits $(P<0.01)$, the majority of patients maintained $\mathrm{Hb}$ values within target levels ( $\geq 11 \mathrm{~g} / \mathrm{dL}) .{ }^{9}$ Anemia secondary to CKD was corrected using EPO in $18.5 \%$ of patients at baseline and in $28.3 \%$ of patients at visit 4 , and to a lesser extent with the use of iron base $(15.2 \%$ at the fourth visit compared to $18.5 \%$ of patients at baseline) (Table 2). Patients received 
Table I Baseline clinical characteristics by staging of CKD in total population $(n=397)$

\begin{tabular}{|c|c|c|c|c|c|c|c|}
\hline Clinical characteristic & Unknown & Stage I & Stage 2 & Stage 3 & Stage 4 & Stage 5 & Total \\
\hline \multicolumn{8}{|l|}{ General } \\
\hline Patient number, n (\%) & $17(4.3)$ & $56(\mid 4.1)$ & $65(16.4)$ & $127(32)$ & $95(23.9)$ & $37(9.3)$ & $397(100)$ \\
\hline Age $($ mean $\pm S D)$ & $49.9 \pm 17.3$ & $55.0 \pm 13.2$ & $64.6 \pm 12.9$ & $71.2 \pm 10.7$ & $73.8 \pm 11.2$ & $70.8 \pm 18.7$ & $67.5 \pm 14.6$ \\
\hline Males, $n(\%)$ & $13(76.5)$ & $32(57.1)$ & $38(58.5)$ & $71(55.9)$ & $45(47.4)$ & $19(51.4)$ & $218(54.9)$ \\
\hline Females, n (\%) & $4(23.5)$ & $24(42.9)$ & $27(4 I .5)$ & $56(44.1)$ & $50(52.6)$ & $18(48.6)$ & $179(45.1)$ \\
\hline Dialysis therapy, n (\%) & - & - & I (I.5) & $\mathrm{I}(0.8)$ & $2(2.1)$ & - & $4(I)$ \\
\hline \multicolumn{8}{|l|}{ Patient origin } \\
\hline General practitioner, n (\%) & $17(100)$ & $36(64.3)$ & $35(53.8)$ & $66(52)$ & $63(66.3)$ & $30(81.1)$ & $247(62.2)$ \\
\hline Specialist, $\mathrm{n}(\%)$ & - & $15(26.8)$ & $21(32.3)$ & $48(37.8)$ & $26(27.4)$ & $3(8.1)$ & $113(28.5)$ \\
\hline Other origin, $\mathrm{n}(\%)$ & - & $5(8.9)$ & $9(13.8)$ & $13(10.2)$ & $6(6.3)$ & $4(10.8)$ & $37(9.3)$ \\
\hline \multicolumn{8}{|l|}{ Reason for hospital visit } \\
\hline Renal failure, n (\%) & - & $12(21.4)$ & $32(49.2)$ & $99(78.0)$ & $78(82.1)$ & $24(64.9)$ & $245(6 \mid .7)$ \\
\hline Hypertension, n (\%) & $7(4 \mid .2)$ & $28(50)$ & $26(40)$ & $4 \mid(32.3)$ & $42(44.2)$ & $26(70.3)$ & $170(42.8)$ \\
\hline Diabetic nephropathy, n (\%) & $4(23.5)$ & II (19.6) & $15(23.1)$ & $25(19.7)$ & $19(20)$ & $16(43.2)$ & $90(22.7)$ \\
\hline Proteinuria, n (\%) & $8(47.1)$ & $10(17.9)$ & $8(12.3)$ & II (8.7) & $7(7.4)$ & $2(5.4)$ & $46(11.6)$ \\
\hline Hematuria, $\mathrm{n}(\%)$ & $2(11.8)$ & $6(10.7)$ & $7(10.8)$ & $4(3.1)$ & $4(4.2)$ & - & $23(5.8)$ \\
\hline Nephrolithiasis, n (\%) & I (5.9) & $4(7.1)$ & II (I6.9) & $6(4.7)$ & $2(2.1)$ & I (2.7) & $25(6.3)$ \\
\hline Previous hospitalization, $\mathrm{n}(\%)$ & $13(76.5)$ & $35(62.5)$ & $50(76.9)$ & $107(84.3)$ & $79(83.2)$ & $32(86.5)$ & $316(79.6)$ \\
\hline \multicolumn{8}{|l|}{ Hospitalization by type } \\
\hline General surgery, n (\%)* & II (84.6) & $26(74.3)$ & $39(78)$ & $80(74.8)$ & $54(68.4)$ & $13(40.6)$ & $223(70.6)$ \\
\hline Cardiological, n (\%) & $2(15.4)$ & $5(14.3)$ & $16(32)$ & $4 I(38.3)$ & $38(48.1)$ & $15(46.9)$ & $117(37)$ \\
\hline General medicine, $\mathrm{n}(\%)$ & $4(30.8)$ & $7(20)$ & $12(24)$ & $24(22.4)$ & $21(26.6)$ & $13(40.6)$ & $81(25.6)$ \\
\hline Other hospitalization, $\mathrm{n}(\%)$ & $5(38.5)$ & $3(8.6)$ & $22(44)$ & $14(13.1)$ & $18(22.8)$ & $8(25)$ & $54(17.1)$ \\
\hline \multicolumn{8}{|l|}{ Biochemical parameters $\ddagger$} \\
\hline Serum creatinine, $n(\%)$ & II (64.7) & $5 I(9 I . I)$ & $61(93.8)$ & $119(93.7)$ & 91 (95.8) & 34 (91.9) & $367(92.4)$ \\
\hline GFR, n (\%) & II (64.7) & $5 I(9 I . I)$ & $58(89.2)$ & $117(92.1)$ & $90(94.7)$ & $35(94.6)$ & $362(9 \mid .2)$ \\
\hline BUN, n (\%) & $7(4 \mid .2)$ & $40(71.4)$ & $53(81.5)$ & 91 (71.7) & $67(70.5)$ & $27(73)$ & $285(71.8)$ \\
\hline $\mathrm{Na}, \mathrm{n}(\%)$ & I (5.9) & $21(37.5)$ & $25(38.5)$ & $40(31.5)$ & $22(23.2)$ & $5(13.5)$ & 114 (28.7) \\
\hline $\mathrm{K}, \mathrm{n}(\%)$ & I (5.9) & $24(42.9)$ & $26(40)$ & $52(40.9)$ & $30(31.6)$ & $10(27)$ & $143(36)$ \\
\hline Total $\mathrm{Ca}^{2+}, \mathrm{n}(\%)$ & I (5.9) & $17(30.4)$ & $22(33.8)$ & $37(29.1)$ & $19(20)$ & $5(13.5)$ & $101(25.4)$ \\
\hline $\mathrm{P}, \mathrm{n}(\%)$ & I (5.9) & $16(28.6)$ & $20(30.8)$ & $36(28.3)$ & $16(16.8)$ & $2(5.4)$ & 91 (22.9) \\
\hline $\mathrm{Hb}, \mathrm{n}(\%)$ & $3(17.6)$ & $30(53.6)$ & $33(50.8)$ & $7 \mid(55.9)$ & $62(65.3)$ & $22(59.5)$ & $221(55.7)$ \\
\hline iPTH, n (\%) & $0(0)$ & $\mathrm{I}(\mathrm{I} .8)$ & $4(6.2)$ & II (8.7) & $5(5.3)$ & $\mathrm{I}(2.7)$ & $22(5.5)$ \\
\hline \multicolumn{8}{|l|}{ Concomitant diseases } \\
\hline Hypertension, n (\%) & $9(52.9)$ & $37(66.1)$ & $46(70.8)$ & $100(78.7)$ & $72(75.8)$ & $27(73)$ & $291(73.3)$ \\
\hline Cardiovascular disease, $\mathrm{n}(\%)$ & I (5.9) & $5(8.9)$ & $15(23.1)$ & $49(38.6)$ & $42(44.2)$ & $13(35.1)$ & $125(31.5)$ \\
\hline Diabetes, $\mathrm{n}(\%)$ & $4(23.5)$ & $12(21.4)$ & $21(32.3)$ & $43(33.9)$ & $26(27.4)$ & $17(45.9)$ & $123(31)$ \\
\hline Dyslipidemia, n (\%) & I (5.9) & $10(17.9)$ & $13(20)$ & $31(24.4)$ & $19(20)$ & $6(16.2)$ & $80(20.2)$ \\
\hline Other disease, $n(\%)$ & $2(11.8)$ & $5(8.9)$ & $9(13.8)$ & $25(19.7)$ & $28(29.5)$ & II (29.7) & $80(20.2)$ \\
\hline \multicolumn{8}{|l|}{ Medication } \\
\hline Antihypertensive, n (\%) & $9(52.9)$ & $36(64.3)$ & $52(80)$ & $110(86.6)$ & $78(82.1)$ & $29(78.4)$ & $314(79.1)$ \\
\hline Diuretic, n (\%) & $5(29.4)$ & $12(21.4)$ & $21(32.3)$ & $62(48.8)$ & $63(66.3)$ & $26(70.3)$ & $189(47.6)$ \\
\hline ACE inhibitor, $\mathrm{n}(\%)$ & $4(23.5)$ & $22(39.3)$ & $28(43.1)$ & $55(43.3)$ & $43(45.3)$ & $7(18.9)$ & $159(40.1)$ \\
\hline ARB, $n(\%)$ & $6(35.3)$ & $13(23.2)$ & $30(46.2)$ & $58(45.7)$ & $39(4 I .1)$ & $16(43.2)$ & $162(40.8)$ \\
\hline Calcium antagonist, n (\%) & $2(11.8)$ & $13(23.2)$ & $17(26.2)$ & $4 I(32.3)$ & $22(23.2)$ & $13(35.1)$ & $108(27.2)$ \\
\hline Beta-blocker, n (\%) & I (5.9) & $9(16.1)$ & $8(12.3)$ & $32(25.2)$ & $18(18.9)$ & $6(16.2)$ & $74(18.6)$ \\
\hline Alpha-blocker, n (\%) & - & $2(3.6)$ & $4(6.2)$ & $13(10.2)$ & $8(8.4)$ & $3(8.1)$ & $30(7.6)$ \\
\hline Antithrombotic, n (\%) & $6(35.3)$ & $9(16.1)$ & $22(33.8)$ & $61(48)$ & $49(51.6)$ & $21(56.8)$ & $168(42.3)$ \\
\hline Statin, n (\%) & $3(17.6)$ & $12(21.4)$ & $21(32.3)$ & $50(39.4)$ & $29(30.5)$ & II (29.7) & $126(31.7)$ \\
\hline Cardiac therapy, n (\%) & - & I (I.8) & $12(18.5)$ & $30(23.6)$ & $22(23.2)$ & $13(35.1)$ & $78(19.6)$ \\
\hline Oral antidiabetic, n (\%) & $\mathrm{I}(5.9)$ & $9(16.1)$ & $13(20)$ & $27(21.3)$ & $14(14.7)$ & $6(16.2)$ & $70(17.6)$ \\
\hline Insulin, n (\%) & I (5.9) & I (I.8) & $4(6.2)$ & $9(7.1)$ & $10(10.5)$ & $8(21.6)$ & $33(8.3)$ \\
\hline Erythropoietin, n (\%) & - & - & $\mathrm{I}(1.5)$ & $9(7.1)$ & $13(13.7)$ & $6(16.2)$ & $29(7.3)$ \\
\hline Vitamin D supplement, $\mathrm{n}(\%)$ & - & $2(3.6)$ & $2(3.1)$ & $12(9.4)$ & $7(7.4)$ & $3(8.1)$ & $26(6.5)$ \\
\hline Iron base, $\mathrm{n}(\%)$ & - & - & $2(3.1)$ & $9(7.1)$ & II (II.6) & $3(8.1)$ & $25(6.3)$ \\
\hline Low protein diet, n (\%) & - & - & $2(3.1)$ & $9(7.1)$ & $6(6.3)$ & I (2.7) & $18(4.5)$ \\
\hline Calcium carbonate, $\mathrm{n}(\%)$ & - & $2(0.5)$ & $2(0.5)$ & $4(0.1)$ & $2(0.5)$ & $\mathrm{I}(0.25)$ & II (2.8) \\
\hline
\end{tabular}

Notes: *Percent calculated from patients who had a previous hospitalization $(n=316)$; ${ }^{\text {}}$ refers to biochemical parameters that were measured at the first (baseline) visit. "Unknown" refers to patients where parameters used to calculate GFR were missing and therefore GFR was unknown.

Abbreviations: CKD, chronic kidney disease; GFR, glomerular filtration rate; BUN, blood urea nitrogen; $\mathrm{Na}$, sodium; $\mathrm{K}$, potassium; Total Ca ${ }^{2+}$, total calcium; $\mathrm{P}$, phosphorus; $\mathrm{Hb}$, hemoglobin; iPTH, intact parathyroid hormone; $\mathrm{ACE}$, angiotensin-converting enzyme; ARB, angiotensin receptor blocker; SD, standard deviation. 
A

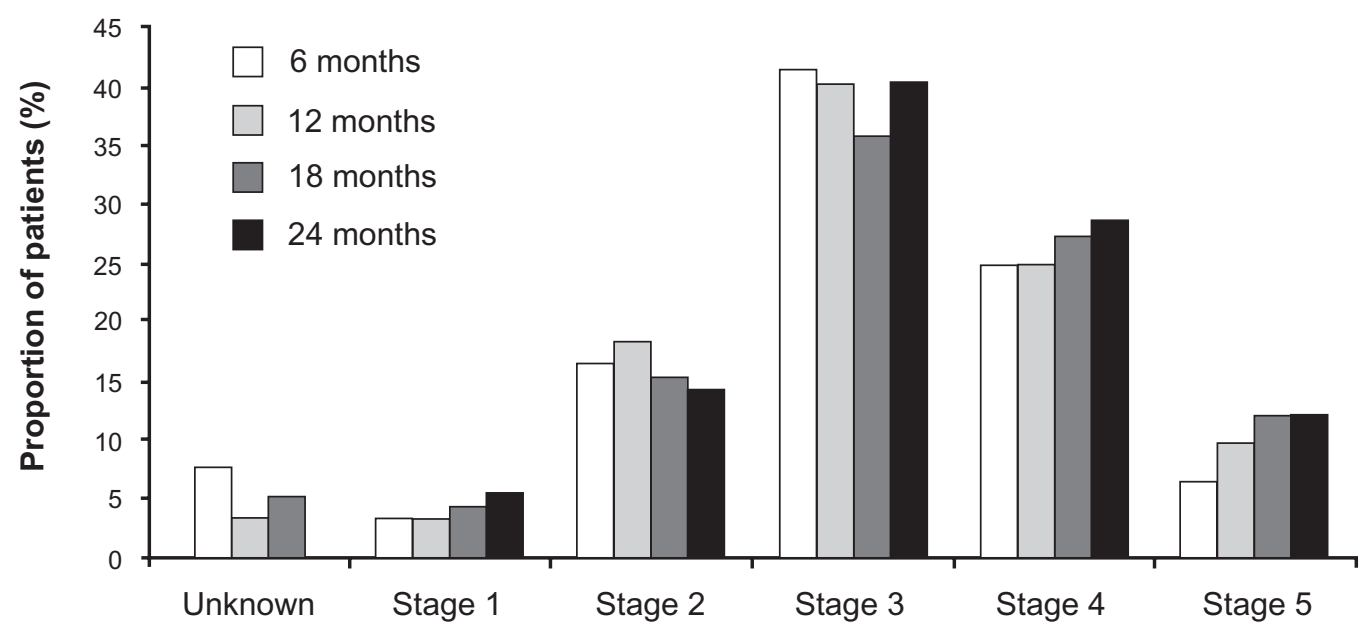

B

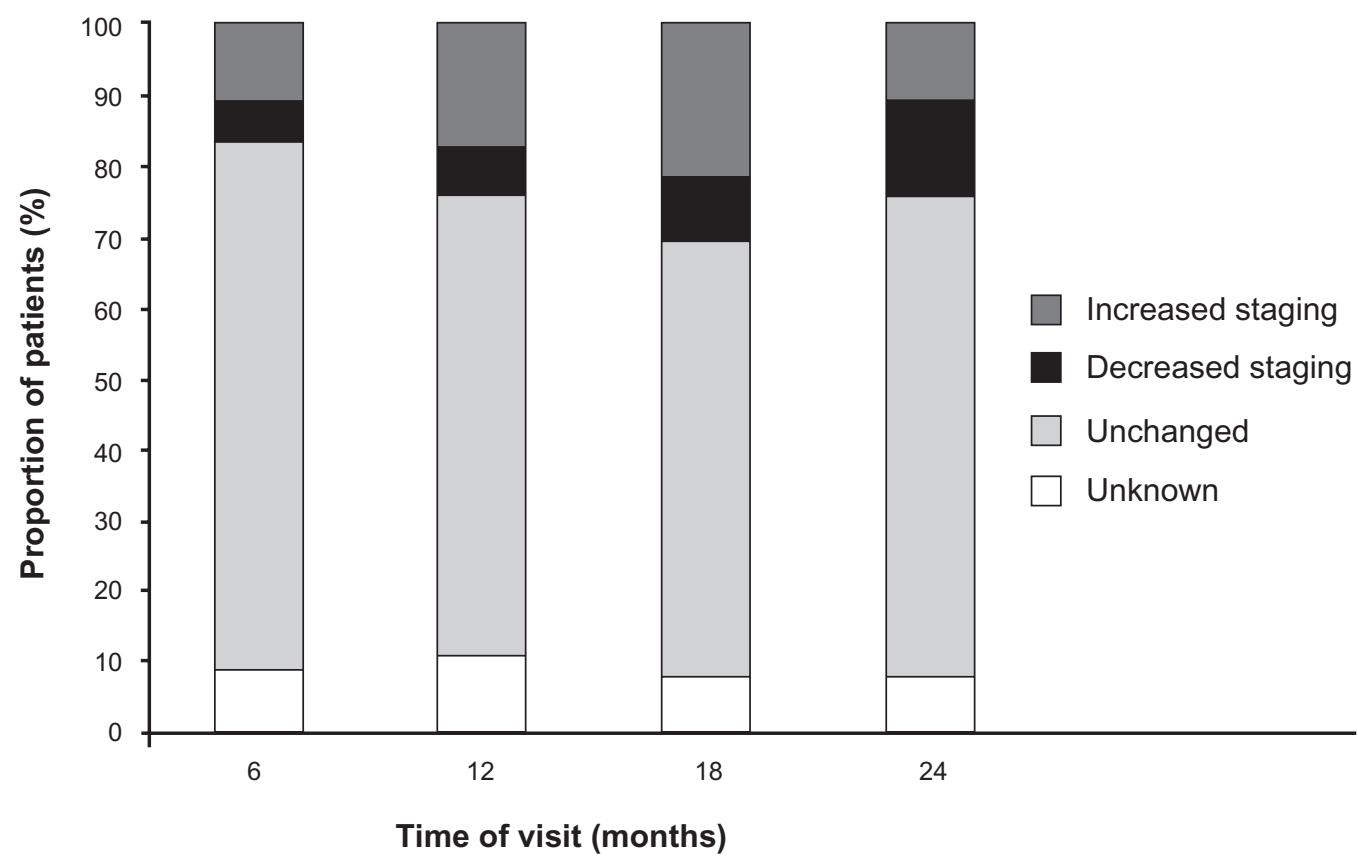

Figure I Staging and variation in CKD staging for patients over the four visits. (A) Staging of CKD in patients over the four visits. (B) Change in CKD staging (relative to baseline) over the four visits.

Note: Data are expressed as percentage and taken from patients who attended all four visits $(n=92)$.

different beta-EPO and darbepoetin. Data are reported using a conversion factor from beta-epoetin to darbepoetin according to Italian Guidelines. ${ }^{16}$ The mean EPO dosage did not significantly change over time $(28.8 \pm 10.5 \mu \mathrm{g} /$ week at 6 months versus $24.2 \pm 13 \mu \mathrm{g}$ /week at 24 months).

Patients treated with EPO are shown by range in levels of $\mathrm{Hb}$ over the four visits (Figure 4). The number of
EPO-treated patients with $\mathrm{Hb}$ levels $<10 \mathrm{~g} / \mathrm{dL}$ decreased from 12 to 24 months and EPO-treated patients with $\mathrm{Hb}$ levels between 10-11 g/dL (below target levels) increased over the study period. As expected, a high proportion of EPO-treated patients had unstable levels of $\mathrm{Hb}(74.2 \%)$ compared to untreated patients $(8.2 \% ; P<0.001)$. The dosage of vitamin $\mathrm{D}$ supplements administered to patients for 


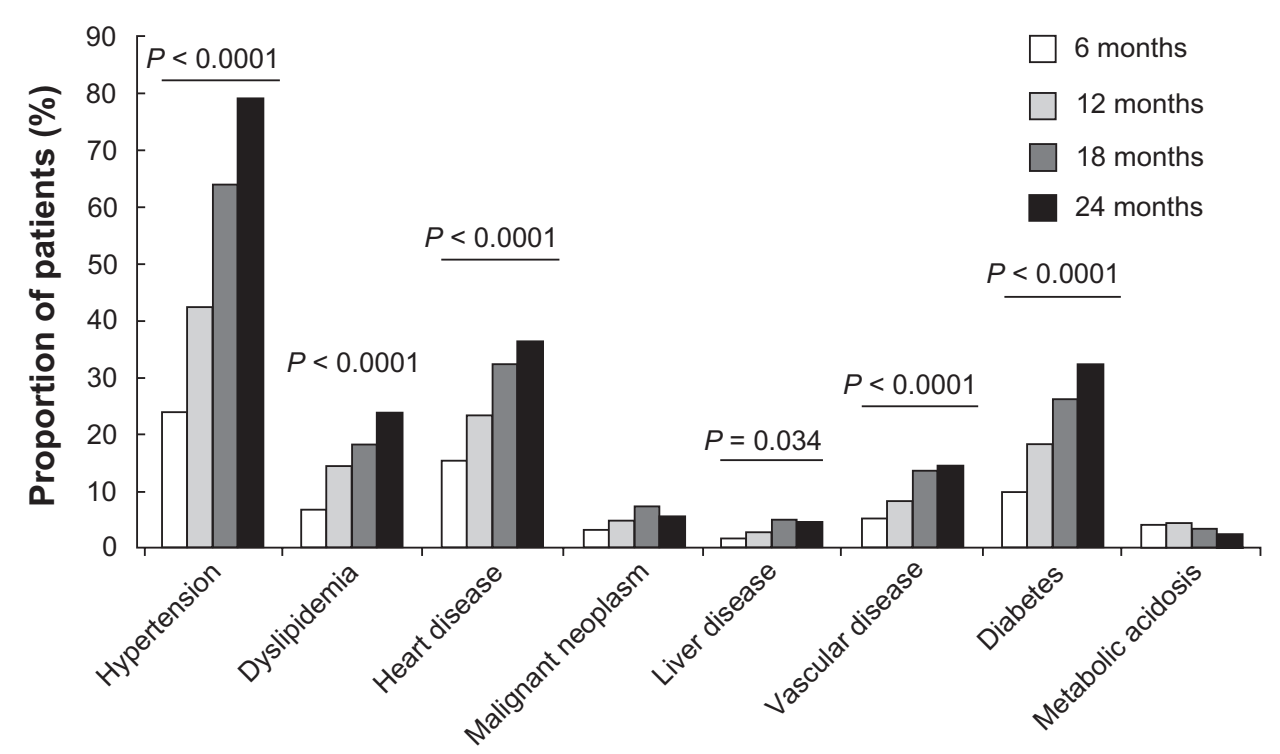

Figure 2 Concomitant diseases diagnosed in patients over the four visits.

Notes: Data are expressed as percentage and taken from the total population $(n=397)$. $P$ values are indicated where significant differences were observed over the four visits (Fisher's exact test).

CKD-MBD did not significantly change over the study period $(1.07 \pm 0.86 \mu \mathrm{g} /$ week at 6 months versus $1.13 \pm 0.91 \mu \mathrm{g} /$ week at 24 months).

\section{Adherence to anemia NKF-K/DOQI guidelines}

More than $80 \%$ of patients maintained target levels for $\mathrm{Hb}$ over the four visits.

\section{Discussion}

The SONDA study was specifically designed to assess the referral to the nephrologist, therapeutic management, and outcome of patients with CKD not on dialysis. This study provides information on the current clinical practice and evidence of individuals seeking advice from the nephrologist, their underlying reasons, and their clinical status. It also yields important data on the (short-to-medium range) development of CKD in the "real world" combined with underlying comorbid conditions and the treatment administered relative to current guidelines.

The high rate of hospitalization before baseline confirms the clinical complexity and higher comorbidity of patients with CKD, especially for diseases of surgical relevance. Although GPs requested creatinine measurements in a high percentage of patients, only a small number of patients had GFR measured or calculated and their disease staging was categorized by their GP. It is worth noting that CKD staging deteriorated in the study population during the first three visits (up to 18 months) and improved at 24 months. It is suggestive that this effect might be attributed to a delayed effect of therapeutic measures undertaken by the specialist. In addition, the number of patients with comorbid diseases increased over the follow-up period. Although calcium, phosphorous, and $\mathrm{Hb}$ levels in the majority of patients did achieve target values according to guidelines over the followup period, there was no observable time-dependent effect following treatment, as seen in other similar studies that were of shorter duration. ${ }^{17,18}$ In the present study, only a limited use of calcium carbonate, vitamin D supplements, and iron base was reported for the management of CKD-MBD. The sparing use of these medications can be partly explained by the fact that these patients have normal values for metabolites such as phosphorous and calcium at baseline. In this regard, the relatively small number of patients receiving treatment for CKD-MBD, with respect to other medication (hypertensive, diuretic, etc) may account for the absence (or masking) of any temporal effect of this treatment on biochemical and electrolyte parameters and the lack of principal data makes it difficult to draw definitive conclusions.

Since it is recognized that transitory reductions in $\mathrm{Hb}$ levels below target range are common and associated with worse outcome in patients with $\mathrm{CKD},{ }^{18-24}$ and only a few studies to date have evaluated $\mathrm{Hb}$ variability in nondialysis CKD patients, ${ }^{18,25,26}$ we specifically aimed to examine temporal change and stability of $\mathrm{Hb}$ in the present study. Our findings suggest that stability of Hb levels (defined as having $\mathrm{Hb}$ values $\geq 11 \mathrm{~g} / \mathrm{dL}$ for the four visits or instable when $\mathrm{Hb}$ values dropped $<11 \mathrm{~g} / \mathrm{dL}$ for at least one visit) in patients 
Table 2 Clinical characteristics for patients that attended four visits

\begin{tabular}{|c|c|c|c|c|c|}
\hline Characteristics & 6 months & 12 months & 18 months & 24 months & $P$ value \\
\hline \multicolumn{6}{|l|}{ General } \\
\hline Age (years) & $65.3 \pm 16.6$ & $65.8 \pm 16.6$ & $66.3 \pm 16.6$ & $66.8 \pm 16.6$ & - \\
\hline Male, n (\%) & $47(51.1)$ & $47(5 I .1)$ & $47(51.1)$ & $47(5 I .1)$ & - \\
\hline \multicolumn{6}{|l|}{ Biochemical parameters } \\
\hline eGFR (mL/min/l.73 m²) & $41.8 \pm 22.9$ & $42.1 \pm 23.5$ & $40.6 \pm 23.9$ & $42.1 \pm 25.6$ & \\
\hline Creatinine $(\mathrm{mg} / \mathrm{dL})$ & $2 \pm 2$ & $1.93 \pm 1.1$ & $2.1 \pm 1.3$ & $2.1 \pm 1.4$ & 0.93 \\
\hline $\mathrm{BUN}(\mathrm{mg} / \mathrm{dL})$ & $77.2 \pm 35.8$ & $77.8 \pm 40.8$ & $83.3 \pm 46.1$ & $87.9 \pm 55.3$ & 0.36 \\
\hline $\mathrm{Na}(\mathrm{mg} / \mathrm{dL})$ & $140.1 \pm 2.7$ & $139.6 \pm 3.8$ & $139.9 \pm 3.6$ & $140 \pm 4.4$ & 0.91 \\
\hline $\mathrm{K}(\mathrm{mg} / \mathrm{dL})$ & $4.7 \pm 0.6$ & $4.7 \pm 0.6$ & $4.7 \pm 0.6$ & $4.8 \pm 0.6$ & 0.72 \\
\hline$P(m g / d L)$ & $3.8 \pm 0.7$ & $3.8 \pm 0.8$ & $3.96 \pm 0.8$ & $3.97 \pm 0.9$ & 0.48 \\
\hline $\mathrm{Ca}^{2+}(\mathrm{mg} / \mathrm{dL})$ & $9.6 \pm 0.5$ & $9.5 \pm 0.5$ & $9.4 \pm 0.6$ & $9.4 \pm 0.8$ & 0.29 \\
\hline $\mathrm{Hb}(\mathrm{g} / \mathrm{dL})$ & $12.6 \pm 1.5$ & $12.5 \pm 1.6$ & $12.5 \pm 1.9$ & $12.3 \pm 1.7$ & 0.84 \\
\hline \multicolumn{6}{|l|}{ Concomitant diseases } \\
\hline Hypertension, n (\%) & $75(8 \mid .5)$ & $79(85.9)$ & $76(82.6)$ & $81(88)$ & 0.33 \\
\hline Cardiovascular disease, n (\%) & $16(17.4)$ & $16(17.4)$ & $16(17.4)$ & $18(19.6)$ & 0.72 \\
\hline Diabetes, $\mathrm{n}(\%)$ & $29(31.5)$ & $31(33.7)$ & $32(34.8)$ & $31(33.7)$ & 0.97 \\
\hline Dyslipidemia, n (\%) & $34(36.9)$ & $41(44.6)$ & $42(45.7)$ & $44(47.8)$ & 0.15 \\
\hline Other disease, n (\%) & $21(22.8)$ & $20(21.7)$ & $20(21.7)$ & $25(27.2)$ & 0.79 \\
\hline \multicolumn{6}{|l|}{ Vascular complications } \\
\hline Ventricular hypertrophy, n (\%) & $19(20.7)$ & $19(20.7)$ & $21(22.8)$ & $26(28.3)$ & 0.2 \\
\hline Arrhythmia during treatment, $\mathrm{n}(\%)$ & $15(16.3)$ & II (I2) & II (I2) & $13(14.1)$ & 0.68 \\
\hline PAD, n (\%) & $5(5.4)$ & $3(3.3)$ & $4(4.3)$ & $5(5.4)$ & 0.91 \\
\hline Cerebrovascular disease, $\mathrm{n}(\%)$ & $7(7.6)$ & $9(9.8)$ & $10(10.9)$ & $11(12)$ & 0.31 \\
\hline Encephalopathy, n (\%) & $2(2.2)$ & $3(3.3)$ & $3(3.3)$ & $3(3.3)$ & 0.68 \\
\hline \multicolumn{6}{|l|}{ Medication } \\
\hline Antihypertensive, n (\%) & $75(8 \mid .5)$ & $79(85.9)$ & $76(82.6)$ & $81(88)$ & 0.33 \\
\hline Diuretic, n (\%) & $56(60.9)$ & $59(64.1)$ & $57(6 \mid .9)$ & $59(64.1)$ & 0.74 \\
\hline ACE inhibitor, $n(\%)$ & $42(45.7)$ & $50(54.3)$ & $51(55.4)$ & $51(55.4)$ & 0.19 \\
\hline ARB, n (\%) & $42(45.7)$ & $42(45.7)$ & $4 I(44.6)$ & $43(46.7)$ & 0.93 \\
\hline Calcium antagonist, n (\%) & $27(29.4)$ & $27(29.4)$ & $29(31.5)$ & $33(35.9)$ & 0.32 \\
\hline Beta-blocker, n (\%) & $19(20.7)$ & $20(2 \mid .7)$ & $21(22.8)$ & $20(21.7)$ & 0.82 \\
\hline Alpha-blocker, n (\%) & $4(4.3)$ & $5(5.4)$ & $5(5.4)$ & $2(2.2)$ & 0.49 \\
\hline Antithrombotic, n (\%) & $43(46.7)$ & $47(5 \mathrm{I} .1)$ & $47(5 \mathrm{I} .1)$ & $49(53.3)$ & 0.4 \\
\hline Statin, $n(\%)$ & $34(36.9)$ & $4 I(44.6)$ & $42(45.7)$ & $44(47.8)$ & 0.15 \\
\hline Cardiac therapy, n (\%) & $29(31.5)$ & $27(29.4)$ & $28(30.4)$ & $27(29.4)$ & 0.8 \\
\hline Oral antidiabetic, n (\%) & $13(14.1)$ & $14(15.2)$ & $13(14.1)$ & $12(13)$ & 0.79 \\
\hline Insulin, n (\%) & $16(17.4)$ & $17(18.5)$ & $19(20.7)$ & $19(20.7)$ & 0.52 \\
\hline Erythropoietin (EPO), n (\%) & $17(18.5)$ & $20(2 \mid .7)$ & $23(25)$ & $26(28.3)$ & 0.09 \\
\hline EPO and iron base, $n(\%)$ & $8(8.7)$ & $8(8.7)$ & $5(5.4)$ & $4(3.3)$ & 0.36 \\
\hline Iron base, $\mathrm{n}(\%)$ & $17(18.5)$ & $18(19.6)$ & $14(15.2)$ & $14(15.2)$ & 0.42 \\
\hline Vitamin D supplement, n (\%) & $18(19.6)$ & $24(26.1)$ & $22(23.9)$ & $23(25)$ & 0.48 \\
\hline Calcium carbonate, n (\%) & $7(7.6)$ & $7(7.6)$ & $3(3.3)$ & $3(3.3)$ & 0.1 \\
\hline
\end{tabular}

Note: Data from patients who attended all four visits $(n=92)$.

Abbreviations: BUN, blood urea nitrogen; $\mathrm{Na}$, sodium; $\mathrm{K}$, potassium; $\mathrm{P}$, phosphorus; $\mathrm{Ca}^{2+}$, total calcium; Hb, hemoglobin; PAD, peripheral artery disease; $\mathrm{ACE}$, angiotensinconverting enzyme; ARB, angiotensin receptor blocker.

was not obtained with use of EPO, regardless if there was a change in the type or dose of drug used. However, due to the low number of patients administered ESAs in our study, these findings should be treated with caution. Unfortunately, it is also recognized that the implementation of guidelines in nephrology is infrequent. ${ }^{27,28}$ Regarding the treatment of anemia in nondialysis-CKD patients, it is possible that nephrologists may be more inclined to give a fixed low dose of ESA, in light of the concerns of the potential negative effects of the use of high doses of ESAs, as well as the risk of exceeding the narrow target range now recommended. ${ }^{9}$ It should be noted that $\mathrm{Hb}$ target values were based on those from $2006 \mathrm{~K} / \mathrm{DOQI}$ guidelines and not on the more recent updates. ${ }^{9}$ In 2009, the Anaemia Working Group of European Renal Best Practice (ERBP) published its first position statement about the $\mathrm{Hb}$ target to aim for with ESAs and on issues that were not covered by K/DOQI in 2006-2007. ${ }^{29}$ This second position paper of the group follows the 


\section{A}

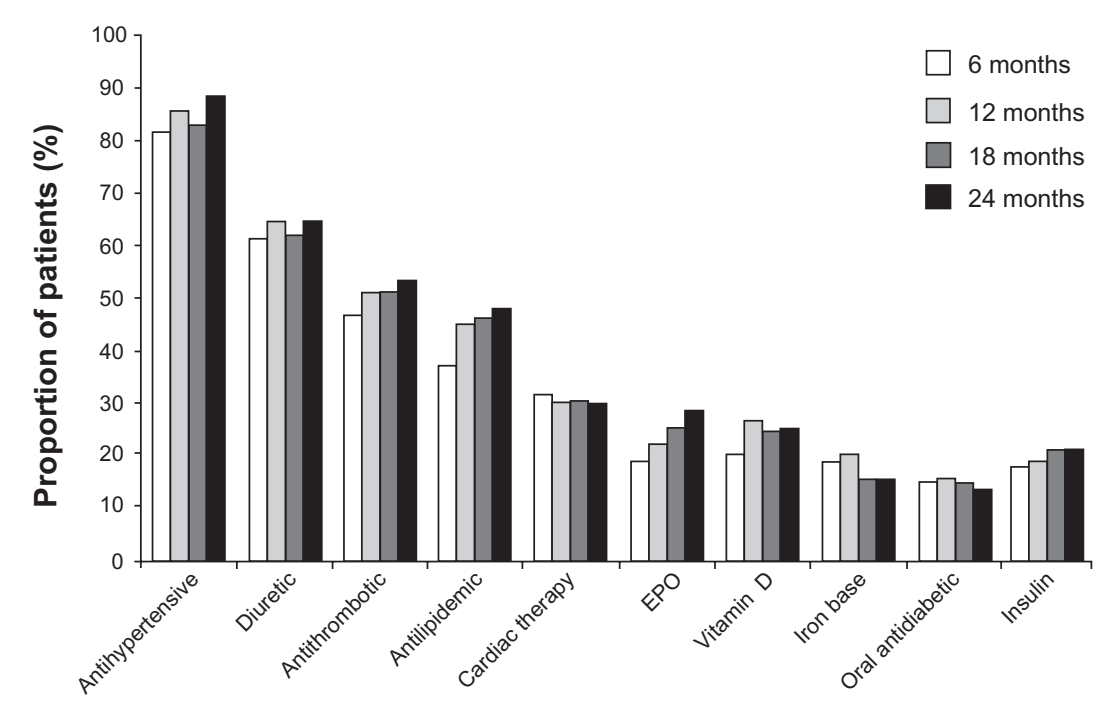

B

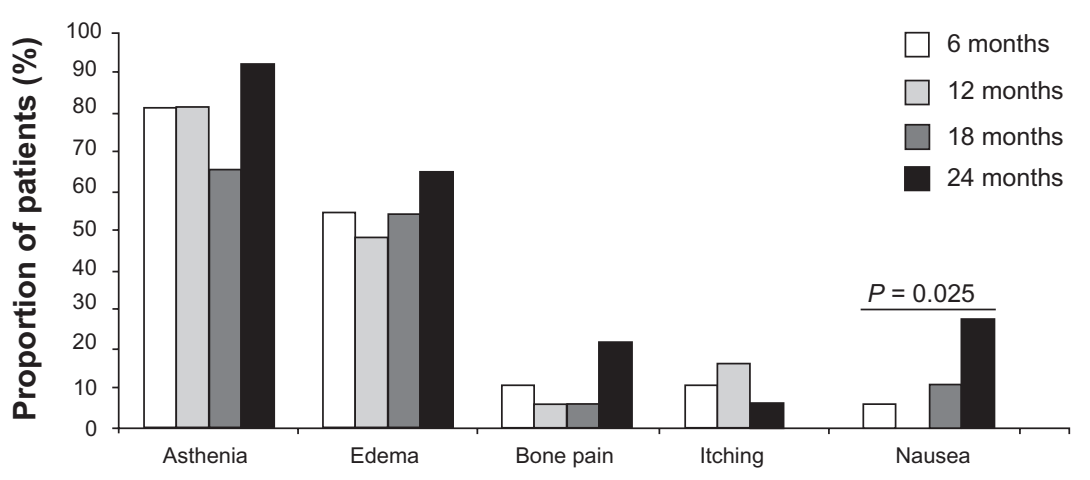

Figure 3 Treatment and adverse events in patients over the four visits. (A) Medication received in patients over the four visits. (B) Adverse events reported in patients over the four visits.

Notes: Data are expressed as percentage and taken from patients who attended all four visits $(n=92)$. $P$ value indicates a significant difference observed over the four visits (Fisher's exact test).

publication of the Trial to Reduce Cardiovascular Events with Aranesp ${ }^{\circledR}$ Therapy (TREAT) Study. ${ }^{30}$ Following the findings of the TREAT study, the Anaemia Working Group of ERBP maintains its view that " $\mathrm{Hb}$ values of $11-12 \mathrm{~g} / \mathrm{dL}$ should be generally sought in the CKD population without intentionally exceeding $13 \mathrm{~g} / \mathrm{dL}$ " and doses of ESA therapy to achieve the target $\mathrm{Hb}$ be considered. Furthermore, it is also recommended that if not already performed, patients with stages $3 \mathrm{~b}, 4$, and 5 CKD should be examined for the presence of anemia. ${ }^{29}$

Table 3 Range in hemoglobin levels in patients over the four visits

\begin{tabular}{llllll}
\hline Hb $(\mathbf{g} / \mathrm{dL})$ & $\begin{array}{l}\mathbf{6} \text { months } \\
(\boldsymbol{n}=\mathbf{7 8})\end{array}$ & $\begin{array}{l}\text { I2 months } \\
(\mathbf{n}=\mathbf{8 7})\end{array}$ & $\begin{array}{l}\mathbf{1 8} \text { months } \\
(\boldsymbol{n}=\mathbf{8 2})\end{array}$ & $\begin{array}{l}\mathbf{2 4} \text { months } \\
(\boldsymbol{n}=\mathbf{7 9})\end{array}$ \\
\hline Not measured & $14(17.9)$ & $5(5.7)$ & $10(12.2)$ & $13(16.5)$ & $\mathrm{P}$ value \\
$<\mathrm{II}$ g/dL, $\mathrm{n}(\%)$ & $6(7.7)$ & $12(13.8)$ & $12(14.6)$ & $18(22.8)$ & 0.018 \\
$\geq \mathrm{II} \mathrm{g/dL,} \mathrm{n} \mathrm{( \% )}$ & $72(92.3)$ & $75(86.2)$ & $70(85.4)$ & $66(83.5)$ & $\mathrm{ns}$ \\
\hline
\end{tabular}

Notes: Data from patients who attended all four visits $(n=92)$. Target levels of $\geq 1 \mathrm{I} \mathrm{g/dL} \mathrm{according} \mathrm{to} \mathrm{K/DOQI} \mathrm{guidelines.}{ }^{9}{ }^{9} 6$ months versus 24 months, Fisher's exact test. Abbreviations: $\mathrm{ns}$, nonsignificant; $\mathrm{Hb}$, hemoglobin. 


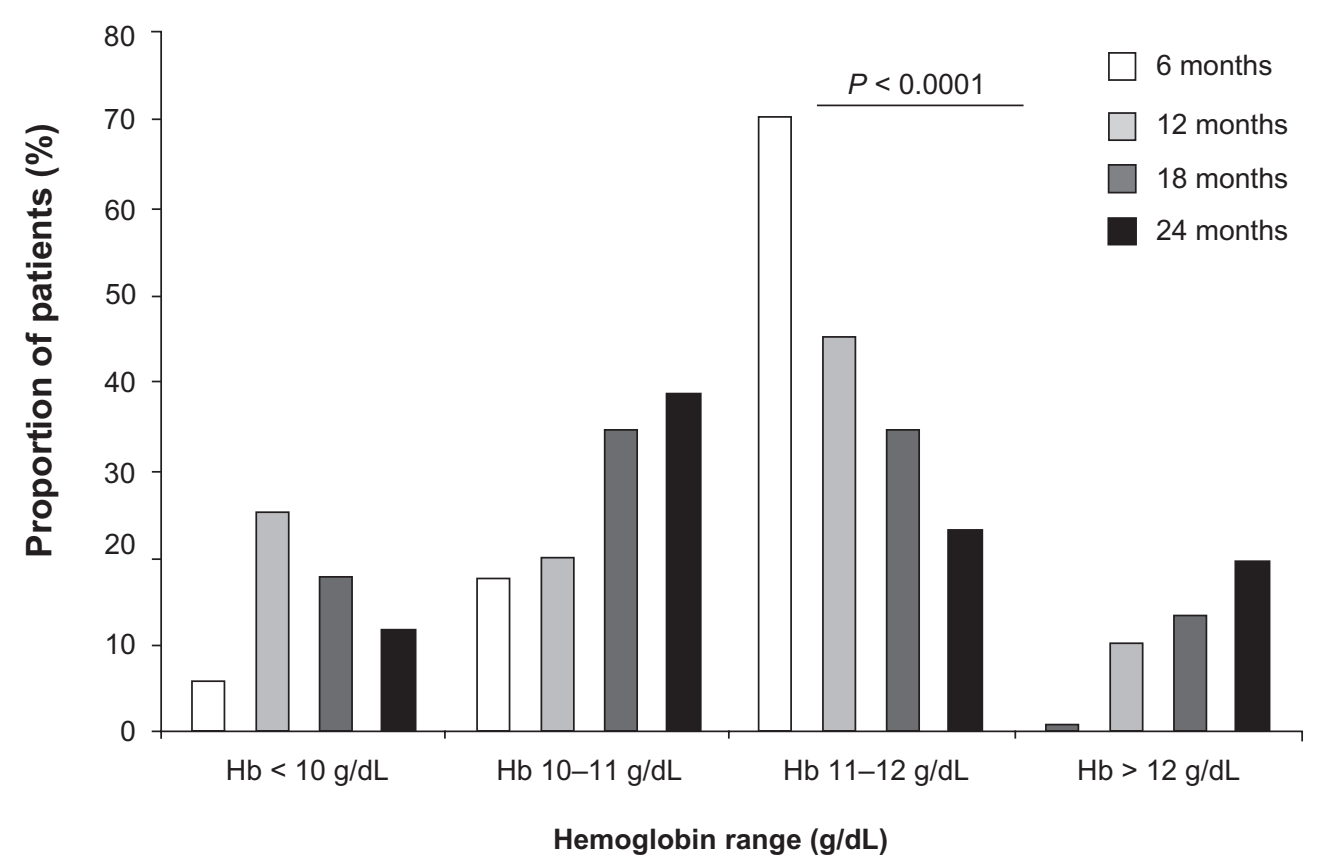

Figure 4 Use of EPO to treat anemia in patients over the four visits. Proportion of patients receiving EPO medication by different levels of $\mathrm{Hb}$ over the four visits. Notes: Data are expressed as percentage and taken from patients who attended all four visits $(n=92)$. $P$ value indicates a significant difference observed over the four visits (Fisher's exact test).

Abbreviations: EPO, erythropoietin; Hb, hemoglobin.

This study is of particular value as it provides longitudinal data (collected retrospectively) over a period of 24 months in patients with CKD. Furthermore, to date, few studies are available that report data on this Italian population. However, there are some potential limitations that need to be addressed. Although the number of patients at baseline was relatively large $(n=397)$, the retrospective and longitudinal nature of this study meant that our analysis was only limited to patients who attended all four visits $(n=92)$. This reduction in the observation number is due to the fact that only patients signing the specific consent for this study and fulfilling all inclusion criteria were enrolled. For this reason, we could not evaluate hard outcomes such as death or renal failure (dialysis). Many of these patients were added recently to the database and therefore the number of retrospective observations was limited. However, although this sample size restricted subgroup analysis, it is in line with similar previous studies. ${ }^{18,26}$ Actually, analysis was also extended to the entire study population over the follow-up period (patients who did not attend all four visits) and results were similar to those presented in this manuscript (data not shown). Staging of CKD was based on eGFR as measured by the abbreviated MDRD method, which is recognized to underestimate GFR at high GFR values. However, this problem is more apparent in the measurement of GFR in healthy individuals, where the prevalence of undiagnosed CKD can be underestimated. ${ }^{31}$ Furthermore, a recent systematic review performed on 12 studies in North America, Europe, and Australia, showed that although the CKD-EPI equation performed better at higher GFRs (approximately $>60 \mathrm{~mL} / \mathrm{min}$ per $1.73 \mathrm{~m}^{2}$ ), the MDRD Study equation actually performed better at lower GFRs. ${ }^{32}$ This is particularly relevant in the present study where the MDRD equation was used to estimate GFR in patients with relatively low GFR (mean eGFR of approximately $40 \mathrm{~mL} / \mathrm{min}$ per $1.73 \mathrm{~m}^{2}$ ). Ideally, more than one measure of GFR should be implemented where possible. It is important to underline that this study was monocentric and therefore may not be representative across the entire Italian peninsula. Consistent with limitations of an observational design, our study provides important clinical insights into the therapeutic management of CKD, but it does not provide direct information on the effect of treatment on patient outcome. Lastly, the database used to perform the SONDA study did not provide data on iPTH and thus, information on secondary hyperparathyroidism was unavailable. Furthermore, the SONDA database did not provide data on proteinuria. This is a particularly important limitation of this study, since proteinuria is a fundamental prognostic marker of CKD progression. Greater attention should be given towards the monitoring of proteinuria in order to evaluate the relative risk of CKD. ${ }^{33}$ 
In summary, management of CKD at the level of the nephrologist is essential for reducing its progression and for providing improved control of secondary diseases. Findings from the SONDA survey indicate that (1) the control of anemia, electrolyte balance mineral metabolism and GFR of CKD patients is insufficient at the level of the GP and nonnephrologist; (2) control of mineral metabolism and proteinuria is insufficient at the specialist level: and (3) improving the coordinated relationship between GP and nephrologists is needed in order to improve therapeutic management of CKD patients. The importance of raising awareness of the management of CKD in both the general practitioner and specialist alike cannot be underestimated, particularly as more and more therapeutic options are becoming available for these patients.

\section{Acknowledgment}

Ion SRL (Bologna, Italy) performed statistical analysis.

\section{Disclosure}

Research conducted in this study was supported by an unrestricted educational grant from Abbott S.r.1. Italy. Dr Anna Maria Costanzo, and Dr Umberto di Luzio Paparatti are employees of Abbott Italy. At the time the study was undertaken, Dr Antonio Gorini was an employee of Abbott Italy. Dr Colin Gerard Egan (on behalf of Primula Multimedia S.r.1.) received fees for manuscript preparation. The authors report no other conflicts of interest in this work.

\section{References}

1. 2001 Report, Volume 1: Dialysis and Renal Transplantation, Canadian Organ Replacement Register, Canadian Institute for Health Information, Ottawa, Ontario; Aug 2001.

2. Kiberd BA, Clase CM. Cumulative risk for developing end-stage renal disease in the US population. J Am Soc Nephrol. 2002;13: $1635-1644$.

3. Valderrabano F, Golper T, Muirhead N, Ritz E, Levin A. Chronic kidney disease: why is current management uncoordinated and suboptimal? Nephrol Dial Transplant. 2001;16(Suppl 7):61-64.

4. Chantrel F, Enache I, Bouiller M, et al. Abysmal prognosis of patients with type 2 diabetes entering dialysis. Nephrol Dial Transplant. 1999;14: 129-136.

5. Levin A, Djurdjev O, Barrett B, et al. Cardiovascular disease in patients with chronic kidney disease: getting to the heart of the matter. $A m J$ Kidney Dis. 2001;38:1398-1407.

6. Levin A. Prevalence of cardiovascular damage in early renal disease. Nephrol Dial Transplant. 2001;16(Suppl 2):7-11.

7. The Renal Team. A Multi-Professional Renal Workforce Plan for Adults and Children with Renal Disease. Recommendations of the National Renal Workforce Planning Group, British Renal Society. 2002. Available from: http:www.britishrenal.org. Accessed March 10, 2012.

8. Xue JL, Ma JZ, Louis TA, Collins AJ. Forecast of the number of patients with end-stage renal disease in the United States to the year 2010. J Am Soc Nephrol. 2001;12:2753-2758.
9. National Kidney Foundation. KDOQI Clinical Practice Guidelines and Clinical Practice Recommendations for Anaemia in Chronic Kidney Disease. Am J Kidney Dis. 2006;47(5 Suppl 3):S11-S146.

10. Besarab A. Resolving the paradigm crisis in intravenous iron and erythropoietin management. Kidney Int Suppl. 2006;101:S13-S18.

11. McClellan W, Aronoff SL, Bolton WK, et al. The prevalence of anaemia in patients with chronic kidney disease. Curr Med Res Opin. 2004;20:1501-1510.

12. Minutolo R, De Nicola L, Mazzaglia G, et al. Detection and awareness of moderate to advanced CKD by primary care practitioners: a crosssectional study from Italy. Am J Kidney Dis. 2008;52:444-453.

13. Locatelli F, Zoccali C; SIR SIN Study Investigators. Clinical policies on the management of chronic kidney disease patients in Italy. Nephrol Dial Transplant. 2008;23:621-626.

14. De Nicola L, Donfrancesco C, Minutolo R, et al. Epidemiology of chronic kidney disease in Italy: current state and contribution of the CARHES study. G Ital Nefrol. 2011;28:401-407. Italian.

15. Kidney Disease: Improving Global Outcomes (KDIGO) CKD-MBD Work Group. KDIGO clinical practice guideline for the diagnosis, evaluation, prevention, and treatment of chronic kidney diseasemineral and bone disorder (CKD-MBD). Kidney Int. 2009;113: S1-S130.

16. Triolo G; Italian Society of Nephrology. Guidelines for the treatment of anemia in chronic renal failure. G Ital Nefrol. 2003;20(Suppl 24): S61-S82. Italian.

17. Mazzaferro S, Brancaccio D, Messa P, et al; on behalf of the FARO Study Group. Management of secondary hyperparathyroidism in Italy: results of the Italian FARO survey. J Nephrol. 2011;24: 225-235.

18. De Nicola L, Conte G, Chiodini P, et al. Stability of target hemoglobin levels during the first year of epoetin treatment in patients with chronic kidney disease. Clin J Am Soc Nephrol. 2007;2:938-946.

19. Rasu RS, Manley HJ, Crawford T, Balkrishnan R. Undertreatment of anemia in patients with chronic kidney disease in the United States: Analysis of national outpatient survey data. Clin Ther. 2007;29: $1524-1534$.

20. Fishbane S, Berns JS. Hemoglobin cycling in hemodialysis patients treated with recombinant human erythropoietin. Kidney Int. 2005;68: $1337-1343$.

21. Ebben JP, Gilbertson DT, Foley RN, Collins AJ. Hemoglobin level variability: Associations with comorbidity, intercurrent events, and hospitalizations. Clin J Am Soc Nephrol. 2006;1:1205-1210.

22. Gilbertson DT, Ebben JP, Foley RN, Weinhandl ED, Bradbury BD, Collins AJ. Hemoglobin level variability: Associations with mortality. Clin J Am Soc Nephrol. 2008;3:133-138.

23. Yang W, Israni RK, Brunelli SM, et al. Hemoglobin variability and mortality in ESRD. J Am Soc Nephrol. 2007;18:3164-3170.

24. Fishbane S, Berns JS. Evidence and implications of haemoglobin cycling in anemia management. Nephrol Dial Transplant. 2007;22: 2129-2132.

25. Boudville NC, Djurdjev O, MacDougall IC, et al. Hemoglobin variability in nondialysis chronic kidney disease: examining the association with mortality. Clin J Am Soc Nephrol. 2009;4:1176-1182.

26. Minutolo R, Chiodini P, Cianciaruso B, et al. Epoetin therapy and hemoglobin level variability in nondialysis patients with chronic kidney disease. Clin J Am Soc Nephrol. 2009;4:552-559.

27. De Nicola L, Minutolo R, Chiodini P, et al; for the Target Blood Pressure Levels in Chronic Kidney Disease (Table in CKD) Study Group. Global approach to cardiovascular risk in chronic kidney disease: reality and opportunities for intervention. Kidney Int. 2006;69: 538-545.

28. Zoccali C, Abramowicz D, Cannata-Andia JB, et al. European Best Practice Guidelines, European Renal Best Practice: European best practice quo vadis? From European Best Practice Guidelines (EBPG) to European Renal Best Practice (ERBP). Nephrol Dial Transplant. 2008;23:2162-2166. 
29. Locatelli F, Covic A, Eckardt KU, Wiecek A, Vanholder R; ERA-EDTA ERBP Advisory Board. Anaemia management in patients with chronic kidney disease: a position statement by the Anaemia Working Group of European Renal Best Practice (ERBP). Nephrol Dial Transplant. 2009;24:348-354.

30. Pfeffer MA, Burdmann EA, Chen CY, et al; TREAT Investigators. A trial of darbepoetin alfa in type 2 diabetes and chronic kidney disease. N Engl J Med. 2009;361:2019-2032.

31. Gorini A, Costanzo AM, Egan CG, di Luzio Paparatti U. Renal status in adult volunteers in central Italy: results from Family Abbott Renal Disease Monitoring Project (FARM) study. J Nephrol. 2011; 25:523-532.
32. Earley A, Miskulin D, Lamb EJ, Levey AS, Uhlig K. Estimating equations for glomerular filtration rate in the era of creatinine standardization: a systematic review. Ann Intern Med. 2012;156:785-795.

33. Gansevoort RT, Matsushita K, van der Velde M, et al; Chronic Kidney Disease Prognosis Consortium. Lower estimated GFR and higher albuminuria are associated with adverse kidney outcomes. A collaborative meta-analysis of general and high-risk population cohorts. Kidney Int. 2011;80:93-104

\section{Publish your work in this journal}

The International Journal of Nephrology and Renovascular Disease is an international, peer-reviewed open-access journal focusing on the pathophysiology of the kidney and vascular supply. Epidemiology, screening, diagnosis, and treatment interventions are covered as well as basic science, biochemical and immunological studies. The journal welcomes original research, clinical studies, reviews \& evaluations, expert opinion and commentary, case reports and extended reports. The manuscript management system is completely online and includes a very quick and fair peerreview system, which is all easy to use. Visit http://www.dovepress.com/ testimonials.php to read real quotes from published authors

Submit your manuscript here: http://www.dovepress.com/international-journal-of-nephrology-and-renovascular-disease-journal 